INEEL/CON-99-01176

PREPRINT

\title{
Residual Stress Determination from a Laser-Based Curvature Measurement
}

\author{
W. D. Swank \\ R. A. Gavalya \\ J. K. Wright \\ R. N. Wright
}

May 8, 2000 - May 11, 2000

\section{International Thermal Spray Conference}

This is a preprint of a paper intended for publication in a journal or proceedings. Since changes may be made before publication, this preprint should not be cited or reproduced without permission of the author.

This document was prepared as a account of work sponsored by an agency of the United States Government. Neither the United States Government nor any agency thereof, or any of their employees, makes any warranty, expressed or implied, or assumes any legal liability or responsibility for any third party's use, or the results of such use, of any information, apparatus, product or process disclosed in this report, or represents that its use by such third party would not infringe privately owned rights. The views expressed in this paper are not necessarily those of the U.S. Government or the sponsoring agency. 


\title{
Residual Stress Determination from a Laser-Based Curvature Measurement
}

\author{
W. David Swank, Rick A. Gavalya, Jill K. Wright, Richard N. Wright \\ Idaho National Engineering and Environmental Laboratory \\ P.O. Box 1625 \\ Idaho Falls, ID 83415-2211
}

\begin{abstract}
Thermally sprayed coating characteristics and mechanical properties are in part a result of the residual stress developed during the fabrication process. The total stress state in a coating/substrate is comprised of the quench stress and the coefficient of thermal expansion (CTE) mismatch stress. The quench stress is developed when molten particles impact the substrate and rapidly cool and solidify. The CTE mismatch stress results from a large difference in the thermal expansion coefficients of the coating and substrate material. It comes into effect when the substrate/coating combination cools from the equilibrated deposit temperature to room temperature. This paper describes a laser-based technique for measuring the curvature of a coated substrate and the analysis required to determine residual stress from curvature measurements. Quench stresses were determined by heating the specimen back to the deposit temperature thus removing the CTE mismatch stress. By subtracting the quench stress from the total residual stress at room temperature, the CTE mismatch stress was estimated. Residual stress measurements for thick $(>1 \mathrm{~mm})$ spinel coatings with a Ni-Al bond coat on 304 stainless steel substrates were made. It was determined that a significant portion of the residual stress results from the quenching stress of the bond coat and that the spinel coating produces a larger CTE mismatch stress than quench stress.
\end{abstract}

\section{Introduction}

Thermally sprayed coatings are fabricated by the accumulation of individual splats of molten spray material onto the coated part. Large temperature differences and differences in the thermal expansion coefficients produce residual stresses that can affect the performance and life of a coating. Residual stresses are comprised of two components. A quench stress develops from individual molten particles impacting and cooling on the substrate. The hot splats adhere to the relatively cold substrate and transfer their thermal energy to the substrate. As the particles cool to the substrate temperature they contract. The contraction is constrained by the underlying substrate and a tensile stress develops in the deposit. In addition to the particle quench stress, there is a contribution to the residual stress that results from the difference in thermal expansion coefficients between the coating and the substrate material. As the coating is applied to the substrate, thermal energy from the depositing spray material and torch gases raise the temperature of the substrate/coating unit. At the end of the coating process, the substrate/coating combination cools from this elevated deposit temperature back to room temperature. Differences in the coefficient of thermal expansion (CTE) between the coating and substrate material result in the overall change in length for each material to be different. Bonding between the substrate and coating constrain these differences in length and a CTE mismatch stress is developed. When the coating is ceramic and the substrate metallic, this contribution typically results in a compressive stress in the coating. The net residual stress depends on the sum of the quenching and CTE mismatch contributions. Measuring and analyzing these stresses can provide future solutions for minimizing residual stresses that are linked to industrial coating failures.

There are several methods used to determine or predict the residual stresses in thermally sprayed coatings. Xray or neutron diffraction is probably the most direct way to investigate residual stresses in coatings [1-3]. It involves measurement of selected lattice plane spacing in a crystalline structure using an $\mathrm{x}$-ray or neutron beam. The penetration depth of x-rays is limited to approximately $50 \mu \mathrm{m}$ in most coating materials of interest [4]. Since neutrons can penetrate large distances through most materials, neutron diffraction has been used to alleviate a number of the problems associated with $\mathrm{x}$-rays. However, the scattering intensities are low for neutron diffraction, making it difficult to obtain data in a reasonable amount of time. Material removal methods (hole drilling or layer removal) measure changes in in-plane strain with strain gauges, as near by layers of the specimen are physically removed [5-8]. The difficulty arises in controlling the material removal from a curved specimen. If plastic 
deformation or damage occurs during material removal, the assumption of linear elastic change in stress state becomes invalid. Mechanical curvature measurements of the coating/substrate unit have been employed extensively over the past few years in thermal spray research $[1,4,9]$. Typically, a specimen is mounted on knife-edges to allow free movement and a displacement sensor measures changes in the distance to the center of the coupon. This technique has the advantage of being simple and inexpensive but is generally limited to measuring curvatures down to about $0.1 \mathrm{~m}^{-1}$. This method has been applied to real time curvature measurements during coating application. However, the relatively high heat fluxes associated with thermal spray coating can cause large thermal gradients in the substrate that result in curvature of the substrate that is not related to the coating itself. In combination with the experimental methods or alone, the residual stress has been modeled using simple 1-dimensional and relatively complicated finite element techniques [8,10-13].

The work presented here describes a new non-contact laser-based technique to measure curvature. The apparatus is integrated with a vacuum furnace making it possible to evenly heat the substrate/coating unit without the effects of oxidation. From the curvature measurements, estimates of the quenching stress, thermal mismatch stress, and the coating CTE are made. Perfect bonding, elastic deformation of the metal, and uniform curvature of the coupon are assumed when estimating stress and CTE values from the curvature measurements. In reality it is likely that debonding, localized plasticity, creep, and/or micro cracking occur. Some of these variables, such as plasticity and creep, can be accounted for by use of more complex finite element method (FEM) calculations. Others remain difficult to quantify.

The model system for this work was a ceramic coating of $\mathrm{MgAl}_{2} \mathrm{O}_{4}$ spinel composition applied to $\mathrm{Ni}-\mathrm{Al}$ bond coated type 304 stainless steel substrates. Spinel was selected as the model ceramic because it is free of phase transformations upon cooling from the deposition temperature. Type 304 stainless steel was used as a substrate material because this alloy has well characterized mechanical properties and resists oxidation.

\section{Experimental Setup and Description}

Sample Preparation. The geometry of specimens was chosen to minimize biaxial stress and promote onedimensional curvature changes. Coupons measuring $12.5 \mathrm{~mm}$ x $76 \mathrm{~mm}$ were cut from $1.5 \mathrm{~mm}$ thick 304 stainless steel sheet. They were cut using an electrical discharge machine (EDM) to avoid inducing residual stress in the coupon that may arise from shearing or mechanical cutting. One side was polished to a mirror finish so that adequate laser light could be reflected and captured for curvature analysis. A type $\mathrm{K}$ thermocouple was laser welded near the edge of the polished surface to obtain real-time temperature measurements during the coating process and curvature measurements. To further reduce any residual stresses in the coupon prior to the coating application, the coupons were not grit blasted as is usually the case for thermally sprayed coatings. Instead, a $\mathrm{Ni}$ - $\mathrm{Al}$ bond coat approximately $0.13 \mathrm{~mm}$ thick was applied in 4 layers to the side opposite the polished surface. The coupons were then thermally sprayed with 24 layers of $\mathrm{MgAl}_{2} \mathrm{O}_{4}$ to form a 1.2 $\mathrm{mm}$ thick spinel coating.

Both Ni-Al and $\mathrm{MgAl}_{2} \mathrm{O}_{4}$ coatings were applied using a Sultzer Metco $9 \mathrm{MB}$ plasma spray torch in laboratory air. The torch was operated at a power level of $36 \mathrm{~kW}$ using 40 standard liters per minute (slm) of argon and $10 \mathrm{slm}$ hydrogen through a 732a/63 anode/cathode combination. Only one end of the substrate was clamped to avoid constraining curvature. The torch was fixed at a standoff distance of $100 \mathrm{~mm}$ while the substrate was rastered through the spray plume to apply the coating. All specimens were cooled with an air jet on the back side.

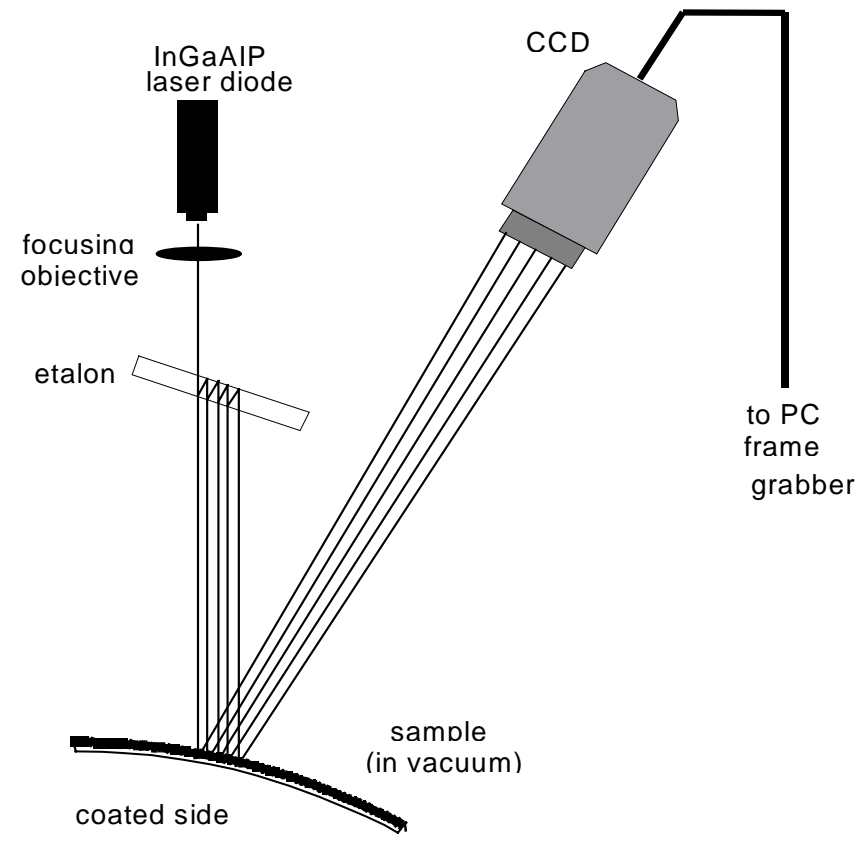

Figure 1. Schematic of laser-based curvature measurement technique.

Laser-based Curvature Measurements. Curvature measurements of the coated specimens were made using a Multi-Beam Optical Sensor (MOS) and specialized software [14]. The system has been historically applied to the measurement of substrate curvature in the thin film microelectronics industry. Curvature measurements begin with a single InGaAIP laser diode beam that enters a solid, fixed spaced, etalon and exits as multiple parallel beams, as shown in figure 1. These parallel beams strike the surface of the sample and are reflected to a charge-coupled device (CCD). The CCD images the entering beams as a onedimensional array of spots and a "frame grabber" periodically captures the reflected images for processing. An optical quality mirror is used to establish a reference against which future spot spacing data is compared. As the beams are reflected from the flat reference mirror they remain parallel with constant spacing. Next, the reference mirror is replaced by a specimen whose curvature is to be measured. As the 
specimen curvature changes, the reflected beams become more convergent or divergent which changes the spacing between the imaged spots. The software tracks and records these changes to calculate changes in specimen curvature.

The specimens curvature, $\kappa$, is determined from the changes in spot spacing using,

$$
\frac{D(t)-D_{0}}{D_{0}}=\frac{2 L \kappa}{\cos \alpha}
$$

where $D_{0}$ is the reference spot spacing distance, $D(t)$ is the distance between spots on the sample at time $t, L$ is the length from the sample to the $\mathrm{CCD}$, and $\alpha$ is the angle of incidence on the sample ( $\alpha=0^{0}$ for normal incidence) [15]. Curvature is related to the radius of curvature, $\mathrm{R}$, by $\kappa=1 / R$.

To illustrate further, stresses that cause the sample to cup on the coated side, as shown in figure 1, cause the once parallel beams to diverge slightly after striking the polished, curved surface and the spacing between spots is greater than the reference spot spacing. Conversely, if the coupon cups on the polished side, the beams converge after striking the curved surface and the spot spacing is less than the reference spot spacing. Curvature is then calculated based on the spot spacing differences between the sample and the reference.

Test Chamber. Curvature measurements were conducted inside a stainless steel vacuum chamber. The chamber is a water-cooled cylinder with sealed ports for instrumentation and power feed-throughs. The MOS curvature measurement system is mounted on the top cover of the chamber. Optical access is provided through a four-inch diameter quartz window. A high vacuum diffusion pump capable of evacuating the chamber to $\approx 10^{-8}$ Torr is connected to the chamber. A 1500-watt cylindrical heater capable of heating to $1000{ }^{0} \mathrm{C}$ rests on supports inside the chamber. An adjustable stand supports the sample at the midpoint of the heater. The sample is able to expand, contract, and curve freely when heated or cooled. A programmable controller is used to set parameters such as setpoint temperature and the heating rate.

Typically, the chamber was evacuated to $\approx 10^{-7}$ torr to reduce oxidation of the polished surface during heating. Curvature measurements were taken at room temperature and at elevated temperatures. Temperature and curvature measurements were recorded in 30-second intervals as the sample was heated. The target temperature was reached in 100 to 150 minutes. Temperature gradients inside the specimen would affect its curvature and lead to erroneous readings. Therefore, once the setpoint temperature was reached, it was maintained for at least 15 minutes to ensure that the temperature throughout the sample was uniform. A final curvature measurement was taken after the specimen passively cooled to room temperature.

Determining stress from curvature. After the curvature has been determined, residual stress in the coating was calculated. Frequently plasma spray applications result in deposits that are thin relative to the substrate, and a thin film approximation is valid [16,17]. However, in this case, thin substrates were used to facilitate curvature of the samples. Therefore, the deposit thickness was similar to the substrate thickness, and a more general set of equations is required [18]. The stress in the deposit as a function of position through the thickness, $\mathrm{x}$, was calculated using

$$
\sigma_{d}=E_{d}\left(\varepsilon_{0}+\varepsilon\right)+E_{d}\left(x-t_{n}\right) \kappa
$$

where $E_{d}$ is the biaxial modulus of the deposit and $\kappa$ is the curvature (or net curvature from one stage to the next) calculated from the spot spacing [19]. At the interface, $x=0$, while at the surface, $x=t_{d}$, the deposit thickness. Assuming both materials remain elastic, the neutral axis is defined as

$$
t_{n}=\frac{E_{d} t_{d}^{2}-E_{s} t_{s}^{2}}{2\left(E_{s} t_{s}+E_{d} t_{d}\right)}
$$

where $E_{s}$ is the biaxial modulus of the substrate and $t_{s}$ is the substrate thickness. The strain terms $\varepsilon$ and $\varepsilon_{o}$ are defined as

$$
\varepsilon=\frac{\kappa\left(E_{s}^{2} t_{s}^{4}+E_{d}^{2} t_{d}^{4}+2 E_{s} E_{d} t_{s} t_{d}\left(2 t_{s}^{2}+2 t_{d}^{2}+3 t_{s} t_{d}\right)\right.}{6 E_{s} E_{d} t_{s} t_{d}\left(t_{s}+t_{d}\right)}
$$

and

$$
\varepsilon_{0}=\frac{\varepsilon E_{d} t_{d}}{E_{s} t_{s}+E_{d} t_{d}}
$$

Determining CTE. Measuring the curvature as a function of temperature also permits calculation of the spinel coating's CTE directly rather than relying on tabulated values for bulk spinel. Thermally sprayed materials can have material properties that vary greatly from those of a bulk material produced by conventional processes.

To determine the CTE at a specific temperature, the curvature variation, $\Delta \kappa$, was observed over some change in temperature, $\Delta \mathrm{T}[20]$. The average CTE for a deposit was calculated using

$$
\alpha_{d}=\frac{I \Delta \kappa}{E_{d} \Delta T t_{d}}\left(\frac{t_{d}}{2}-t_{n}\right)^{-1}+\alpha_{s}
$$

where $\alpha_{d}$ and $\alpha_{s}$ are the CTE of the deposit and substrate, respectively, with $I$ representing the moment of inertia of the sample. Note that this analysis requires a modulus value as input, which to date has been the tabulated value for bulk spinel. Future work will include experimentally determining the modulus of the thermally sprayed spinel coating which may change the calculated CTE values. In this analysis, E and 
CTE are also assumed constant in the temperature range of 22 $-250{ }^{0} \mathrm{C}$.

\section{Results and Discussion}

Initial curvature measurements were taken of uncoated coupons and then after each coating was deposited on the coupons. Based on the curvature measurements, stresses in the coatings were subsequently calculated. The coated samples were then heated to determine the quenching and CTE mismatch stress components of the total residual stress. Coefficients of thermal expansion for the spinel coatings were also determined based on measurements taken during heating.

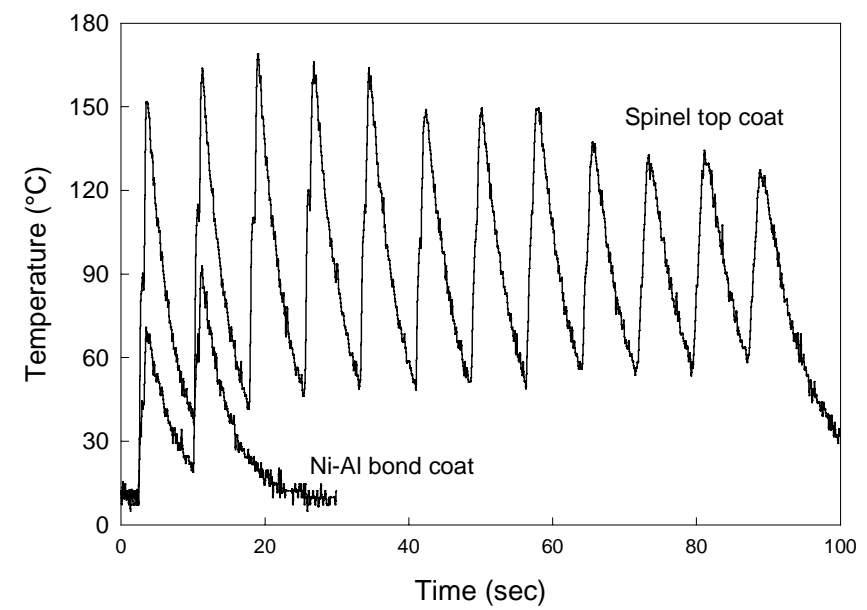

Figure 2: Substrate temperature during Ni-Al bond coat and spinel coat applications.

Figure 2 shows the history of the coupon temperature during the plasma spray application of the bond coat and spinel coat. The plot shows how the substrate temperature cycled as 4 layers of the bond coat and 24 layers of the spinel coat were applied. The maximum temperature, $90^{\circ} \mathrm{C}$, was taken to be the deposit temperature from which the bond coat and substrate cool to develop the CTE mismatch stress. In the case of the spinel coating, $150^{\circ} \mathrm{C}$ was taken as the deposit temperature. There is some uncertainty in these temperature measurements because they were made on the backside of the coupon. Due to the high heat flux associated with the plasma spray coating process, the temperature on the coated surface was higher than the measured values.

Initially, the curvature of an uncoated coupon was very close to zero. After applying the bond coat, the specimen's curvature was relatively high. Figure 3 shows the $\mathrm{Ni}$-Al bond coated sample as having a curvature of approximately 0.24 . The curve labeled "Bond coat" shows how the curvature of the bond coated sample remained nearly constant as it was heated to the deposit temperature of $90^{\circ} \mathrm{C}$. At the deposit temperature both the coating and substrate material were assumed to be at their original lengths and the CTE mismatch stress was removed. Therefore, the remaining curvature in the specimen was due to the quench stress. Because the CTE for Ni-Al and stainless steel are similar and the deposition temperature was only $70^{\circ} \mathrm{C}$ above room temperature, the curvature change related to the CTE

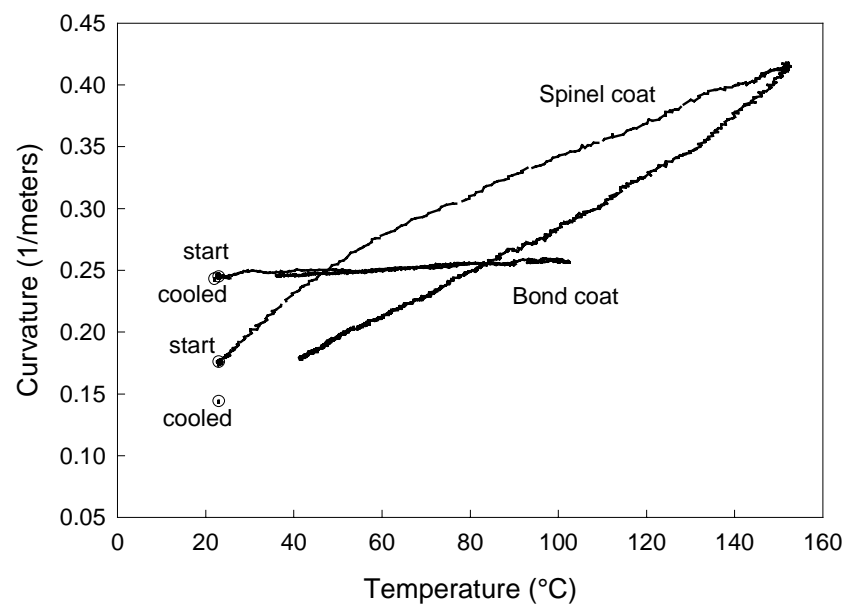

Figure 3: Specimen curvature during heating cycles inside the test chamber.

mismatch stress was small.

Figure 3 also shows the change in curvature for a spinel coated specimen that was heated to its deposit temperature. After the spinel coating was applied to a bond coated sample, its curvature was reduced, indicating the total residual stress was less. As it was heated from room temperature to the deposit temperature of $150^{\circ} \mathrm{C}$, the $\mathrm{CTE}$ mismatch stress was removed leaving only the relatively high quench stress. As expected, the large difference in coefficients of thermal expansion between the ceramic and metallic materials resulted in a significant curvature change indicating the CTE mismatch stress was a significant portion of the total residual stress. In the case of the spinel coating, the specimen curvature did not return to its original value after being heated in the chamber. In fact, the curvature was consistently less, demonstrating that some mechanism for stress relief such as de-bonding or micro cracking occurred during the heating cycle. This stress relief was estimated to be $10 \%$ of the quench stress values presented here and is a subject of future investigations.

Figures 4 shows the stress at the surface of the bond coat and at the interface between the bond coat and substrate as a function of temperature. In figures 4 and 5 the error bars indicate the standard deviation in the data taken and the lines through the data are simple curve fits to aid visualization of the trends. Residual stress for the bond coated samples was calculated by using the net change in curvature from a virgin coupon to the bond coated coupon at elevated temperatures. The bond coat was relatively thin and therefore there was only a small difference between the interface and surface stress. Stress at the deposit temperature of $90^{\circ} \mathrm{C}$ was taken as the quench stress and the difference between the total residual stress at room temperature and the quench stress is a measure of the CTE mismatch stress. As expected in this case, this component of the total residual stress was small.

The bond coated curvature at room temperature was used as the reference or initial curvature for calculating the 
residual stresses in the spinel coating. Since the spinel coating was relatively thick and the sample was bent, stress varied significantly as a function of position through the thickness of the coating (figure 5). At room temperature the residual stress

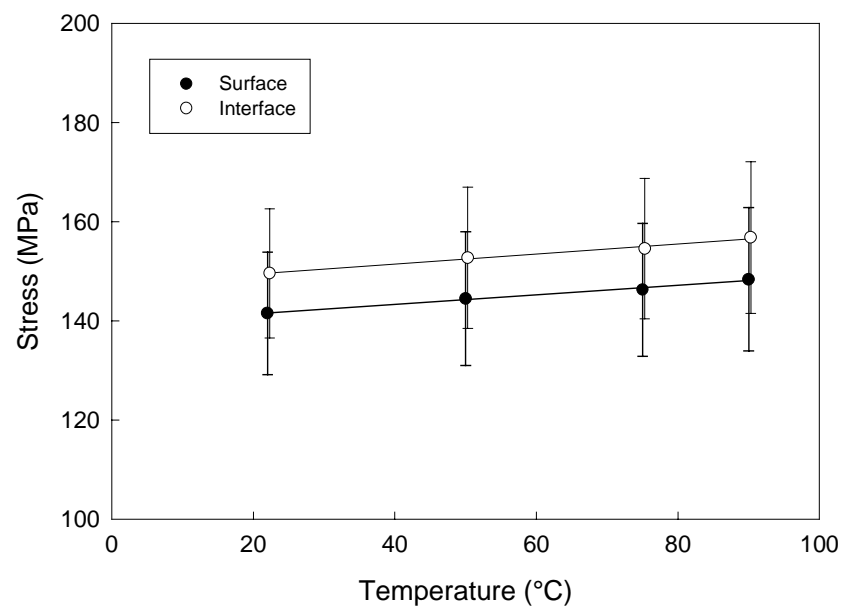

Figure 4: Stress as a function of temperature for the Ni-Al bond coat.

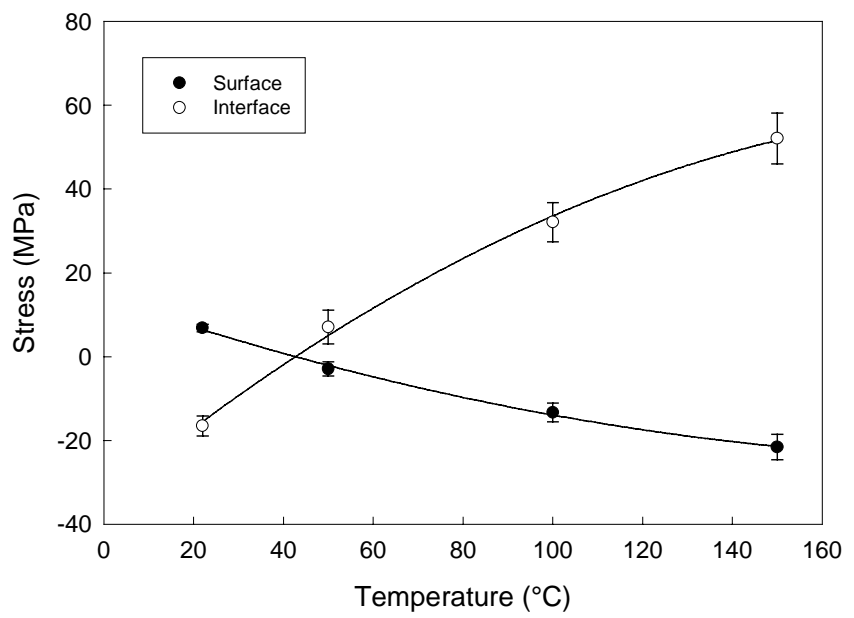

Figure 5: Stress as a function of temperature for the spinel coating.

at the interface between the spinel and substrate was compressive due to the large CTE mismatch. However, when the CTE mismatch stress was removed from the coating by heating the specimen to the deposit temperature, the residual stress at the interface changed from compressive to the tensile quench stress. At the coating surface, the total residual stress was initially tensile and as the specimen was heated, removing the CTE mismatch stress, the stress at the surface became compressive.

Table 1 summarizes the relative magnitudes of the different stresses for the surface and interface of each coating material. The theoretical maximum values for the quenching stress can be approximated by

$$
\sigma_{Q \max } \approx E_{d} \alpha_{d}\left(T_{m p}-T_{d}\right)
$$

where $E_{d}$ is the biaxial modulus of the deposit, $\alpha_{d}$ is the CTE of the deposit, $\mathrm{T}_{\mathrm{mp}}$ is the melting point of the sprayed material and $T_{d}$ is the deposit temperature [4]. For most materials this theoretical maximum stress is $>1 \mathrm{GPa}$. Here the quench stress was determined to be significantly lower. The reason for this is twofold. First, the biaxial modulus was taken as the value for bulk material, when in fact the modulus for the material in the form of a thermally sprayed coating may be much lower. Secondly, there are various stress relaxation mechanisms at work while the quenching process was taking place. Ceramic materials may undergo extensive micro cracking and metallic deposits are prone to plastic yielding or creep. A similar result has been observed previously [18], with an $\mathrm{Al}_{2} \mathrm{O}_{3}$ coating dominated by CTE stress and a Ni-based coating dominated by quench stress.

Table 1: Coating stress (MPa).

\begin{tabular}{|c|c|c|c|}
\hline Location & $\begin{array}{c}\text { Total } \\
\text { residual } \\
\text { stress }\end{array}$ & $\begin{array}{c}\text { Quench } \\
\text { stress }\end{array}$ & $\begin{array}{c}\text { CTE } \\
\text { mismatch } \\
\text { stress }\end{array}$ \\
\hline \hline $\begin{array}{c}\text { Bond coat } \\
\text { surface }\end{array}$ & 142 & 148 & -6 \\
\hline $\begin{array}{c}\text { Bond coat } \\
\text { interface }\end{array}$ & 150 & 156 & -6 \\
\hline $\begin{array}{c}\text { Spinel } \\
\text { surface }\end{array}$ & 7 & -22 & 29 \\
\hline $\begin{array}{c}\text { Spinel } \\
\text { interface }\end{array}$ & -17 & 52 & -69 \\
\hline
\end{tabular}

Table 2 shows coefficients of thermal expansion for the spinel coating calculated from curvature measurements at various temperatures. The calculated values compare well to those tabulated for bulk spinel, which range from $7.5 \times 10^{-6}$ at $127^{\circ} \mathrm{C}$ to $8.4 \times 10^{-6}$ at $327^{\circ} \mathrm{C}$ [21]. Note that this analysis requires a modulus value as input, which to date has been the tabulated value for bulk spinel. Future work will include experimentally determining the modulus of the thermally sprayed spinel coating, which may change the calculated CTE values. In this analysis, $\mathrm{E}$ and $\mathrm{CTE}$ are also assumed constant over the range of measurement temperatures, $250^{\circ} \mathrm{C}$ to room temperature.

Table 2: Measured CTE of spinel coating

\begin{tabular}{|c|c|c|}
\hline $\begin{array}{c}\text { Measurement } \\
\text { Temperature }\left({ }^{\circ} \mathrm{C}\right)\end{array}$ & $\begin{array}{c}\text { Radius of } \\
\text { Curvature (m) }\end{array}$ & $\begin{array}{l}\text { CTE of deposit } \\
\text { from } \mathrm{T}_{\mathrm{n}-1} \text { to } \mathrm{T} \\
\left(\mathrm{x} 10^{-6} /{ }^{\circ} \mathrm{C}\right)\end{array}$ \\
\hline 22 & -0.156 & - \\
\hline 100 & -0.353 & 5.71 \\
\hline 150 & -0.432 & 7.59 \\
\hline 200 & -0.503 & 7.93 \\
\hline 250 & -0.556 & 8.59 \\
\hline
\end{tabular}




\section{Summary and Conclusions}

The MOS laser-based curvature measurement system has been successfully applied to thick thermally sprayed coatings. By integrating the curvature measurement system with a vacuum furnace it was possible to uniformly heat and thermally cycle specimens while measuring curvature changes. Quench and CTE mismatch stresses for Ni-Al bond coats and relatively thick spinel coatings were determined from the curvature measurements. Residual stresses in the $\mathrm{Ni}$ Al bond coat were dominated by the quench stress. The large difference in coefficients of thermal expansion between the spinel and stainless substrate resulted in the CTE mismatch stress being a more significant contributor to the total residual stress in the spinel coating.

Determining the quench and CTE mismatch stress will establish bench marks for computational models. These models, in combination with residual stress measurements, will result in a better understanding of coating failures and ultimately improved coating and process design. It should be possible to engineer coatings for a specific service temperature. For example, by properly controlling the substrate temperature, the level of CTE mismatch stress at the coating service temperature could be matched to the expected quench stress resulting in a coating with little or no residual stress. This would significantly improve coating performance and life expectancies.

Further studies into more accurate material properties of thermally sprayed coating materials, specifically the elastic modulus, are planned. Work is currently being carried out to understand the stress relaxation mechanisms during thermal cycling.

\section{Acknowledgment}

This work was supported by the U.S. Department of Energy, Assistant Secretary for Environmental Management, under DOE Idaho Operations Office Contract No. DE-AC0799ID13727.

\section{References}

1. N. Baradel, L. Bianchi, F. Blein, A. Freslon, M. Jeandin, M. Ceretti, J. Lu, "Evaluation of Residual Stresses Within Plasma-Sprayed Zirconia (ZrO2O3 8\%wt) Coatings", pp. 1623-1627 of Thermal Spray-Meeting the Challenges of the $21^{\text {st }}$ Century, Ed. C. Coddet, Pub. ASM International, Materials Park, OH-USA, 1998 1693+ pages.

2. R. Ahmed, M. Hadfield, S. Tobe, "Residual Stress Analysis in Thermal Spray Coated Rolling Elements", pp. 875-883 of Thermal Spray: Practical Solutions for Engineering Problems, Ed. C.C.Berndt, Pub. ASM International, Materials Park, OH-USA, 1996, 992+ pages.

3. A. H. Bartlett, R.G. Castro, "Residual Stress in Net-Shape Plasma Sprayed Tubes. Measurement, Modeling and Modification", pp. 841-845 of Thermal Spray: Practical Solutions for Engineering Problems, Ed. C.C.Berndt, Pub.
ASM International, Materials Park, OH-USA, 1996, 992+ pages.

4. T.W. Clyne, S.C. Gill, Residual Stresses in Thermal Spray Coatings and Their Effect on Interfacial Adhesion: A Review of Recent Work, J. Thermal Spray Technology Vol.5 No.1, 1996, p.401-418.

5. D.J. Greving, J.R. Shadley, and E.F. Rybicki, Effects of Coating Thickness and Residual Stresses on the Bond Strength of ASTM C633-79 Thermal Spray Coating Test Specimens, J. Thermal Spray Technology Vol.3 No.4, 1994, p.371-378.

6. D.J. Greving, E.F. Rybicki, and J.R. Shadley, ThroughThickness Residual Stress Evaluations for Several Industrial Thermal Spray Coatings Using a Modified Layer-Removal Method, J. Thermal Spray Technology Vol.3 No.4, 1994, p.379-388.

7. R.T.R. McGrann, J.A. Graves, E. F. Rybicki, J.R. Shadley, W.J. Brindley, "Effects of Substrate Temperature and Thermal Cycles on Residual Stresses in Yttria Stabilized Zirconia Thermal Barrier Coatings", pp. 885-890 of Thermal Spray: Practical Solutions for Engineering Problems, Ed. C.C.Berndt, Pub. ASM International, Materials Park, OH-USA, 1996, 992+ pages.

8. G. Jonsson, C. Persson, "Analysis of the Stress State in Thermal Barier Coatings during A Thermal Cycle", pp. 897-901 of Thermal Spray: Practical Solutions for Engineering Problems, Ed. C.C.Berndt, Pub. ASM International, Materials Park, OH-USA, 1996, 992+ pages.

9. A.C. Leger, A. Grimaud, P. Fauchais, C. Catteau, "New Set-Up to Measure Residual Stresses during Plasma Sprayed Coating Formation and Cooling”, pp. 891-896 of Thermal Spray: Practical Solutions for Engineering Problems, Ed. C.C.Berndt, Pub. ASM International, Materials Park, OH-USA, 1996, 992+ pages.

10. A.C. Leger, A. Haddadi, B. Pateyron, G. Delluc, A. Grimaud, F. Nardou, P Fauchais, "Residual Stresses During Coating Generation: Plasma Sprayed Alumina Coatinng on XC38 Measurements and Calculations", pp. 895-903 of Thermal Spray-Meeting the Challenges of the $21^{\text {st }}$ Century, Ed. C. Coddet, Pub. ASM International, Materials Park, OH-USA, 1998 1693+ pages.

11. H. Gruhn, W. Fischer, C. Funke, W. Mallener, D. Stover, "Residual Stress Calculation by Finite Element Methods", pp. 869-874 of Thermal Spray: Practical Solutions for Engineering Problems, Ed. C.C.Berndt, Pub. ASM International, Materials Park, OH-USA, 1996, 992+ pages.

12. S. C. Gill, T.W. Clyne, "Residual Stress Modelling and Characterization of Thermally Sprayed Ceramic Coatings", in High Performance Ceramic Films and Coatings, Ed. P. Vincenzini, Elsevier, 1991, PP. 339-352.

13. J.K. Wright, J.R. Fincke, R.N. Wright, W.D. Swank, D.C. Haggard, "Experimental and Finite Element Investigation of Residual Stresses Resulting from the Thermal Spray Process", pp.187-192 of Thermal Spray Science and Technology, Eds. C.C. Berndt, S. Sampath, Pub. ASM International, Materials Park, OH-USA, 1995, 774+pages. 
14. k-Space Associates, Inc., Ann Arbor, Michigan.

15. J. A. Floro, E. Chason and S. R. Lee, "Real Time Measurement of Epilayer Strain Using a Simplified Wafer Curvature Technique," Materials Research Society Symposium Proceedings Vol. 406, 1996, pp. 491-496.

16. G.G. Stoney, Proc. R. Soc. London Ser. A 82, 172(1909).

17. P.H. Townsend, D.M. Barnett, T.A. Brunner, Elastic Relationships in Layered Composite Media with Approximation for the Case of Thin Films on a Thick Substrate, J. Appl. Phys. 62(11), 4438-4444 (1987).

18. O. Kesler, M. Finot, S. Suresh and S. Sampath, "Determination of processing-induced stresses and properties of layered and graded coatings: experimental method and results for plasma-sprayed $\mathrm{Ni}-\mathrm{Al}_{2} \mathrm{O}_{3}$ " Acta Materialia, 42(2) (1997) 3123-3134.

19. C. H. Hsueh and A. G. Evans, Residual stresses in metal/ceramic bonded strips, Journal of the American Ceramic Society, 68(5) (1985) 241-248.

20. O. Kesler, J. Matejicek, S. Sampath, S. Suresh, T. Gnaeupel-Herold, P. C. Brand, H .J. Prask, "Measurement of residual stress in plasma-sprayed metallic, ceramic and composite coatings" Materials Science and Engineering, A257 (1998) 215-224.

21. Y. S. Touloukian, R. K. Kirby, R. E. Taylor, T. Y. Lee (Eds.), Thermophysical Properties of Matter, Vol. 13: Thermal Expansion in Nonmetallic solids, Plenum, New York, 1977. 